\title{
LA TEORÍA DE LA METÁFORA DE PAUL RICOEUR EN CONTEXTO
}

\author{
ÁNGEla PÉREZ CASTaÑERA \\ IES Luis de Morales (Arroyo de la Luz, Cáceres)
}

Resumen

Este artículo se propone abordar un tema esencial para la teoría de la literatura y para la filosofía del lenguaje. A medio camino entre ambas, hay una corriente de pensamiento que considera que el lenguaje es esencialmente metáfora y que, con el paso del tiempo, ha perdido su capacidad para metaforizar y se ha anquilosado expresivamente. En esta línea se encuentran autores de lo más diverso que han intentado aproximarse al tema por diferentes caminos. Gary Lachman, apoyado en Owen Barfield, facilita una presentación actual del problema desde un punto de vista literario y, podría calificarse así, intuitivo; Nietzsche logró conceptualizarlo modélicamente, y Ricoeur consigue explicar de manera técnica por qué se produce el fenómeno, cómo podría ser revertido y cómo recuperar, por tanto, desde el lenguaje mismo su poder metaforizante y su posibilidad de redescripción del mundo.

Palabras clave: metáfora, poesía, lenguaje, redescripción del mundo, verdad metafórica, Ricoeur.

\section{PAUL RICOEUR'S THEORY OF METAPHOR IN CONTEXT}

\begin{abstract}
This article aims to address an essential theme for the theory of literature and for the philosophy of language. Halfway between the two, there is a current of thought that considers that language is essentially a metaphor and that, with the passage of time, it has lost its ability to metaphorize and has become expressively stagnant. In this line, we can see the most diverse authors who have tried to approach the subject in different ways. Gary Lachman, relying on Owen Barfield, offers a current presentation of the problem from a literary point of view and, as it could also be described, intuitive one; Nietzsche managed to conceptualize it in an exemplary way, and Ricoeur manages to technically explain why the phenomenon occurs, how it could be reversed and how to recover,
\end{abstract}


therefore, from the language itself its metaphorizing power and its possibility of redescribing the world.

Keywords: metaphor, poetry, language, redescription of the world, metaphorical truth, Ricoeur.

\section{LACHMAN/BARFIELD}

Gary Lachman narra el cambio de consciencia de Owen Barfield respecto al lenguaje y la poesía: en una lección sobre el acusativo latino el joven Barfield se encontró con la frase Cato, octoginta annos natus, excessit e vita. Esa metáfora de la muerte, «se despidió de la vida», le hizo comprender que se podía disfrutar del lenguaje en sí mismo, no solo por los hechos o ideas que transmite, y que las metáforas de la poesía o creación literaria eran las felices responsables de ello (Lachman, 2013: 245$246)^{1}$.

Esa «súbita y emocionante» sensación que le produjo el descubrimiento del uso metafórico del lenguaje dio lugar a que publicara en 1928, con treinta años, su famosa Poetic Diction, que tanto influyera, por ejemplo, en Tolkien. Ambos fueron compañeros en los Inklings, al igual que C.S. Lewis entre otros autores relevantes. Esta obra aún sigue influyendo en un espacio literario sui generis, como el de Lachmann, quien sin embargo es heredero de una tradición anglosajona espléndida: R. W. Emerson, Walt Whitman, William James, Joseph Campbell, Colin Wilson, etcétera.

En Poetic Diction ya se encuentran las ideas básicas de Barfield sobre varios conceptos esenciales. En primer lugar, la metáfora: el uso metafórico del lenguaje genera percepciones nuevas de la realidad. En segundo lugar, sobre la poesía, el lenguaje metafórico por excelencia. También en torno al lenguaje mismo, pues considera que todo lenguaje es esencialmente metafórico-poético ${ }^{2}$. Por último, la idea de que el lenguaje ha ido

1 Para este tema del lenguaje, la metáfora y la poesía, Lachman repite esencialmente las ideas de Owen Barfield, sobre todo las expuestas en Saving the Appearences (1965), el libro preferido por Barfield mismo y por el público, y en Owen Barfield and the Origin of Language (1976), una conferencia autobiográfica que dio ese año sobre su propia obra.

${ }^{2}$ Sirvan como ejemplo de esas ideas básicas de Barfield (1928: 25, 40, 72-73), respectivamente: "appreciation of poetry involves a 'felt change of consciousness'»; "the most 
perdiendo su capacidad metafórica o poética. Las metáforas envejecen o se fosilizan, dice Lachman, que cita para la ocasión la celebérrima sentencia de R. W. Emerson: «el lenguaje es poesía fósil». Tanto los tropos retóricos, meramente ornamentales, como las argucias conceptuales, exclusivamente racionalistas, han ido diluyendo el origen poético del lenguaje. Se ha alambicado en cosmética retórica o en conceptos que no se refieren más que al consenso racional de mundo de hoy (Lachman, 2013: 243-253, 266-272).

\section{NIETZSCHE}

En el fondo, ningún uso del lenguaje trata con objetos inmediata e ingenuamente perceptibles, pues el lenguaje condiciona siempre la propia percepción de las cosas: las palabras no son las cosas, defendía ya Gorgias, más bien al contrario, como afirma el relativismo lingüístico de hoy. En el juego esencial del lenguaje entre palabra y cosa se basa su necesaria condición metafórica a la vez que el motivo de su decadencia, ambos puestos de relieve por las reflexiones filosóficas post-racionalistas sobre el lenguaje que inició Nietzsche. Para el filósofo, el lenguaje comienza así: « ¡Un estímulo nervioso, trasladado a una imagen! Primera metáfora. ¡La imagen, a su vez, traspuesta en un sonido! Segunda metáfora. Y en cada caso un salto total de una esfera a otra completamente distinta y nueva» (Nietzsche, 1970: 546). El concepto vendría a ser «el residuo de una metáfora», y "la ilusión inherente a la traslación artística de un estímulo nervioso en imágenes, sería, si no la madre, sí la abuela de todo concepto» (Nietzsche, 1970: 549). La tesis de base es, efectivamente, que la metáfora va diluyéndose o petrificándose -esas dos imágenes, aparentemente opuestas, utiliza Nietzsche- en concepto.

Ese es el sino del lenguaje desde su origen: primero, no es lo real lo que mienta, solo es metáfora suya, aunque al menos, en principio, metáfora inmediata al estímulo que provoca la percepción de las cosas;

conspicuous point of contact between meaning and poetry is metaphor»; "men do not invent those mysterious relations between separate external objects and between objects and feelings, which it is the function of poetry to reveal»: restaurar esa «direct perceptual experience», esa «unidad conceptual» perdida entre cosas y palabras, objetos y sentimientos, es la labor del «language of poets in so far as they create true metaphors». 
segundo, cada vez se aleja más de esa inmediatez, de modo que se va convirtiendo en un «entramado colosal» («tejido desmesurado», dice Barfield) de metáforas cada vez más flácidas: traslaciones o interpretaciones de interpretaciones de interpretaciones (y así sucesivamente), que han perdido el rastro de su origen y de su propia entidad (una primera traslación inmediata) y que se transforman en las verdades y mentiras con las que el ser humano vive seguro en sus convenciones cotidianas, inconsciente de su condición cognoscitiva, mantenida por un lenguaje olvidado de sí, que es ya como una «necrópolis de las percepciones» o un «ingente columbario de los conceptos» (Nietzsche, 1970: 553 ss.).

La «poesía fósil» de Emerson parece una metáfora desvaída ante las geniales contundencias acostumbradas de Nietzsche (1970: 550-551):

Únicamente gracias al olvido de ese primitivo mundo de metáforas, a la solidificación y petrificación de una masa de imágenes que en un tiempo brotó cual lava incandescente del poder primario de la fantasía humana [...] vive [el hombre] con cierta tranquilidad, seguridad y consecuencia: si pudiera escaparse, aunque nada más fuera por un instante, de las paredes de la cárcel de esta creencia se acabaría inmediatamente su «autoconciencia».

El ser humano soporta la tensión de «ser arrastrado por las súbitas impresiones, por las intuiciones», de donde surgen las metáforas originariamente, generalizando «todas esas impresiones en conceptos desleídos, fríos, para uncir a ellos el carro de su vida y acción» y subsistir así convencionalmente. "Diluir las metáforas intuitivas en un esquema, disolver una imagen en un concepto»: ese es el afán moderno humano (Nietzsche, 1970: 548-549).

Sin citar ni a uno ni a otro, ni atisbar las profundas razones de cada uno, aunque dentro de la hermosa tradición referida, Lachman coincide con Nietzsche y Ricoeur en que se percibe un empobrecimiento del lenguaje por la pérdida de la inmediatez a la vivencia de donde surge originariamente en ambos la metáfora, que después se convierte en concepto adocenado, para Nietzsche, o en mero adorno, para Ricoeur. Coincide también en las perspectivas optimistas del último de recuperar 
metafóricamente la viveza del lenguaje. Nietzsche no es tan optimista ${ }^{3}$. Lachman y su entorno, demasiado ${ }^{4}$. Lo extraordinario en Ricoeur es que no es ni una cosa ni otra: simplemente demuestra, en un brillante ejercicio de lingüística, teñida de cierta filosofía, que la metáfora es más que un adorno retórico y menos que un arrebato extático del lenguaje.

\section{PAUl Ricoeur}

$\mathrm{Al}$ «ocaso de la retórica» dedica Ricoeur el estudio II de su libro La metáfora viva, y ese ocaso se refiere en general a lo mismo que la decadencia del propio lenguaje, poéticamente fósil, de que hablan Emerson y

${ }^{3}$ No lo es si se tienen en cuenta su temor a que nunca nos desembarazaremos de los conceptos metafísicos que ha generado nuestra cultura (la «historia de un error») porque seguimos creyendo en su gramática engañadora: "metafísica del pueblo», «rutina» $\mathrm{O}$ "hechizo» que nos cierra otras posibilidades de interpretación de lenguaje y mundo fuera de la moderna racionalista (cfr. respectivamente: Crepúsculo de los ídolos, «La razón en la filosofía», \& 5; Gaya ciencia, \& 354; Más allá del bien y del mal, «De los prejuicios de los filósofos», \&17, 20). Esta desconfianza nietzscheana en la gramática impregna todo el análisis del lenguaje del siglo XX hasta hoy (Reguera, 2018: 175 ss.). De cualquier modo, Nietzsche mantiene cierto optimismo a pesar de sus afanes nihilistas. Era admirador de Emerson. Pone, significativamente en este sentido, como motto a la primera edición de 1882 de Die fröhliche Wissenschaft, una cita, levemente alterada en su traducción alemana, del primero de los Essays (1841) emersonianos («History»): "Dem Dichter und Weisen sind alle Dinge befreundet und geweiht, alle Erlebnisse nützlich, alle Tage heilig, alle Menschen göttlich» -cf. la cita original de Emerson (1950: 123-144, 128)-. Verdad es que la suprime en la segunda edición de 1887, donde ya aparece, por cierto, el citado parágrafo 354 , así como el subtítulo de «la gaya scienza».

${ }^{4}$ Piensan en una especie de (imposible) regreso a la Antigüedad y a una forma de consciencia seguramente irrecuperable. Para Lachman, el de la Antigüedad era un mundo del que la consciencia humana participaba y del que no estaba separada, como hoy, por un invisible muro de alienación, dice. El tipo de mundo que «veían» entonces no era el mundo exterior bien definido y objetivo, constituido por cosas diferenciadas, independientes e impermeables con que nosotros tropezamos cada día. "Los hombres estaban como 'mezclados' con su entorno, aunque nunca hubieran utilizado una palabra tan abstracta para referirse al mundo en el que se encontraban inmersos, indistintos. Formaban parte de la 'naturaleza', habían evolucionado con ella, eran figuras de su tapiz viviente, y no, como nosotros, átomos endurecidos e independientes que van chocando contra todo en una especie de caja ilimitada...» (Lachman, 2013: 267, 253). No podemos volver a un paraíso así, casi homínido, podría decirse. Pero que quede al menos una bella ilusión, como la de la utopía de estas palabras de Barfield (1928: 44-45): «[...] as language grows older, it must necessarily become richer and richer as poetic material: it must become intrinsically more and more poetic [...] from being mere labels for material objects, words gradually turn into magical charms». 
Nietzsche, o retóricamente cosmético, como diría ahora Ricoeur, aludiendo a la equiparación platónica -contra sofistas- de la retórica con la cosmética, en tanto teoría puramente ornamental del tropo.

Por amputación de sus dos partes principales (la teoría de la argumentación y la de la composición), la retórica se ha ido reduciendo progresivamente a la teoría de la elocución, o del estilo; después, a la de la clasificación de figuras, y esta, a su vez, a una teoría de los tropos. La decadencia de la retórica, evidente desde tal perspectiva, proviene de un error inicial que afecta a esa disciplina en sí misma y que es debido, en principio, a lo que Ricoeur llama «la dictadura de la palabra en la teoría del significado»: el privilegio abusivo concedido a la palabra, al nombre o a la denominación, frente a la frase y al discurso. En el primer caso, la metáfora sería un mero tropo, «una desviación que afecta al significado de la palabra»; en el segundo, «un hecho de predicación», «una atribución insólita a nivel del discurso-frase» (Ricoeur, 1980: 71 ss.). «Seule la théorie de la métaphore-énoncé, en replaçant la figure dans le cadre de la théorie du discours, peut rouvrir la problématique du sens et de la référence que la réduction au mot a fermée» (Ricoeur, 1975: 219). El paso general de la métaphore-mot a la métaphore-enoncésería el lema general de la recuperación de la metáfora de su decadencia, que persigue Ricoeur vivificándola.

No es lógico ni pertinente, en efecto, reducir la metáfora a cosmético o a fósil; la metáfora es mucho más: en el fondo oscuro de ella palpitan y siguen palpitando el mito, la consciencia, la imaginación, lo originario, el símbolo. Se incardina en un discurso que responde a una forma de vida profundamente humana y desde el que condiciona, a su vez, esa forma de vida. Redescribe de algún modo lo real, dirá Ricoeur, que acude también a sus reconocidos análisis del poder del mito y del símbolo ${ }^{5}$ para

${ }^{5}$ Dichos análisis son en muchos aspectos semejantes y complementarios a los de Joseph Campbell, autor especialmente interesante en lo que respecta a metáfora, símbolo y mito. Cabe mencionar, como ejemplo, unas páginas de Las extensiones interiores del espacio exterior, quizá su libro más teórico y, dentro de su inmensa bibliografía, el más esclarecedor para la función de la metáfora en el lenguaje mítico y literario (Campbell, 2013: 69-80, 110-116 y 126-127 sobre mito y metáfora; 153-159 y 177-191 sobre arte y metáfora). Destacaremos una idea interesante para este tema: al interpretar un mito como metáfora nos relacionamos no solo con una figura literaria o religiosa específica; el mito es metáfora asimismo de nuestras propias experiencias y de nuestro mundo; metáfora que nos convierte en materia simbólica a nosotros mismos, semejante a la materia 
invitarnos a explorar los numerosos niveles del lenguaje en los que se esconde el significado que la imaginación lingüística -o la consciencia de Lachman- va creando y recreando mediante procesos metafóricos. En ellos, el lenguaje «se extiende a sí mismo hasta sus verdaderos límites, siempre descubriendo nuevas resonancias dentro de sí mismo» (Ricoeur, 1980: 251). Los ecos de dichas resonancias modelan lo real desde el interior del lenguaje.

Esa es la base del poder fundamental del lenguaje literario en la construcción del mundo que percibimos y que imaginamos: hacer que implosione metafóricamente, abriéndose a nuevos aspectos, dimensiones y horizontes suyos propios, desde los que redescribir (redécrire) ${ }^{6}$ el mundo. El mundo exterior no es una realidad objetiva en sentido positivista, ni la de un estado del alma en sentido emocionalista, dice Ricoeur; esa alternativa solo se plantea desde el reduccionismo científico. La poesía ve las cosas de otro modo: «el sentimiento poético, en sus expresiones metafóricas, manifiesta la indistinción de lo interior y lo exterior». La reciprocidad de base para esa indistinción de lo interior y lo exterior se muestra en la correspondencia entre «la objetividad de las texturas poéticas» de lo real y «los esquemas poéticos de la vida interior». Correspondencia, reciprocidad e indistinción que dan el sentido último al juego definitivo de lo real y el lenguaje, de lo exterior y lo interior, y que abocan a otras sorprendentes formulaciones -sorprendentes por su utilidad explicativa a pesar de su insólita enunciación- de Douglas Berggren, como «realidad

shakespeariana de los sueños de que estamos hechos (La tempestad). El mito nunca es real, pero nosotros tampoco. La materia simbólica de la metáfora viva ricoeuriana también añade un plus de sentido peculiar (el realmente humano) al yo, y al lenguaje y mundo en que habita y que le habitan. Por lo que importa en este punto concreto del mito y el símbolo, de Ricoeur habría que consultar fundamentalmente «La función simbólica de los mitos» (Ricoeur, 2004: 311-323). Véase también el capítulo «Meaning and Myth» (Barfield, 1928: 59 ss.; para mito y lenguaje metafórico o poético: 63-64, 72-73 y 80; y como ejemplo típico de su pensamiento: 69-71, donde, comentando las tesis de Macaulay y Jespersen sobre abstracción y lenguaje poético, Barfield encuentra la solución en una tercera vía: "It is this: that these poetic and apparently 'metaphorical' values were latent in meaning from the beginning»-esto es, desde el comienzo mítico del pensar-). Finalmente, dentro de nuestro contexto, remitimos a los ensayos "Bios and Mythos: Prolegomena to a Science of Mythologie» de J. Campbell, "Notes on Mythopoeia» de Ph. Wheelwright y «The Arquetypes of Literature» de N. Frye (estos dos últimos autores citados por Ricoeur) en Vickery (1966: 15-24, 59-66 y 87-98, respectivamente).

${ }^{6}$ Probablemente un neologismo. En la traducción en español se vierte como «redescribir» y se nominaliza como «redescripción» (Ricoeur, 1980: 14-15, 293-343). 
textural»: «la palabra poética solo 'esquematiza' metafóricamente los sentimientos cuando pinta 'texturas de mundo' que se convierten en retratos de la vida interior». Expresado de otro modo: la textura de lo real es una esquematización metafórico-poética de los sentimientos, un retrato de lo interior, pues, y la palabra poética sólo es metafórica, solo es tal, cuando sale al mundo y se retrata en él. Se utilizan otras muchas expresiones, que veremos, orientadas todas, en general, a una concepción «tensional» de la verdad metafórica, que es lo importante ${ }^{7}$.

\subsection{Camino a la verdad metafórica}

De la mano de Émile Benveniste, de la Retórica general del Grupo de Lieja, de Jakobson y de otros muchos ${ }^{8}$, Ricoeur va explicando o desvelando la naturaleza de la metáfora a saltos en profundidad hacia su fondo. La metáfora no es solo desplazamiento y extensión del sentido de las palabras, una designación desviada de ellas; es también un enunciado atrevido referido al mundo. Es necesario liberarla de algún modo del lenguaje, donde se anquilosa como mero ornato. Hay que darle perspectiva desde el lenguaje, sin salir de él, porque las referencias del lenguaje no tienen otro mundo que el suyo propio, otro género de realidad que la lingüística; aunque condicionen la perspectiva humana general de lo real y del mundo, son palabras y ficciones. Esto se desarrolla paso a paso en un camino analítico-lingüístico, pergeñado en general por Benveniste, que funda la lógica del paso de la palabra, como mero signo léxico, a la frase, como unidad mínima de sentido, y de ella al discurso (poema, relato, ensayo), referido ya en cada caso al mundo, descriptivo y constitutivo de él.

Desde la estructura del texto literario, desde el lenguaje pues, ya se puede plantear el nexo de lo que se dice en el lenguaje con el mundo fuera

${ }^{7}$ Ricoeur (1980: 331; 1975: 309-310). Prikett $(1986: 221,75)$ explica también la relación del pensamiento de Ricoeur con el del americano Berggren, señalando cómo la teoría de la metáfora de Ricoeur «is largely derived» del «seminal essay» de Berggren, The use and abuse of Metaphor, que, naturalmente, cita Ricoeur, haciéndolo, además, en el momento crucial de su libro, al final del apartado 4 del estudio VII, "Modelo y metáfora», como paso al decisivo 5, "Hacia el concepto de 'verdad metafórica'», donde se consuma el salto semántico y heurístico, el salto a la referencia y a la verdad.

${ }^{8}$ Entre los que se cuenta Barfield y su invocada Poetic Diction (Ricoeur, 1975: 271, 314). 
del lenguaje, es decir, cuestiones de referencia y de verdad con respecto a lo real. Y ello, a su vez, condiciona lo real mismo, que no es ni puede ser percibido y explicado más que desde un lenguaje y sus condicionantes propios (de poema, relato o ensayo). Real es simplemente aquello de lo que se puede decir con sentido que es «real» dentro de un contexto lingüístico determinado. El relativismo lingüístico, es decir, la dependencia que lo real tiene del lenguaje, es evidente de forma definitiva en el reino literario de la ficción, que, a pesar de ser ficción, condiciona lo real. Así, el idealismo de Don Quijote, el sino trágico de Don Juan o el de Hamlet, y el afán desmedido de conocimiento de Fausto son aspectos paradigmáticos -míticos, metafóricos- del sentido y entramado de lo real.

En este camino de paso del nivel semiológico al semántico y al hermenéutico, la metáfora acaba interesando esencialmente por su referencia directa a la realidad y por su poder de redescribirla al referirse a ella. Esta redescripción se produce dentro del marco que pone modélicamente de manifiesto el això era $i$ no era con que empiezan los cuentos mallorquines, los cuales Ricoeur menciona citando directamente de Jakobson. A través de esta expresión se muestra perfectamente el estatus ontológico de la ficción, situado entre el ser y el no ser, entre mundos que esta hace ser y no ser al mismo tiempo. Se trata de «la paradoja de la cópula es»", la lógica paradójica de la metáfora o de la sutil ironía de la ficción; paradoja e ironía que teñirán necesariamente la salida del lenguaje al mundo en la referencia y la verdad metafóricas.

Lo paradójico no es absurdo ni contradictorio, simplemente no se somete a la lógica reduccionista del racionalismo. Al mundo paradójico del es-y-no-es lo caracterizan peculiaridades que superan tanto la lógica positivista como la emocionalista: virtualidad habitable, presencia tácita, coalescencia tensa, referencia desdoblada, plusvalía semántica. Estas expresiones no son meros oxímoros retóricos, sino buenas pruebas de que

\footnotetext{
${ }^{9}$ Ricoeur (1975: 388): «La référence dédoublée, disions-nous, signifie que la tension caractéristique de l'enonciation métaphorique est portée à titre ultime par la copule est. Être-comme signifie être et ne pas être. Cela était et cela n'était pas [...] la distinction du sens relationnel et du sens existentiel, au cœur même de l'être-copule, était-elle l'indice d'une reprise possible par le discours spéculatif de la dialectique de l'être qui a sa marque apophantique dans le paradoxe de la copule est. Par quel trait le discours spéculatif sur l'être répondra-t-il au paradoxe de la copule, au est/n'est pas apophantique?» (cf. Ricoeur, 1980: 414). Esa es la cuestión que interesa en Ricoeur, que en general se podría resumir en: apofántica paradójica frente a retórica cosmética.
} 
el lenguaje ha de extenderse hasta sus límites y forzarlos cuando quiere expresar algo conceptualmente no acostumbrado, en este caso la estructura de la realidad del mundo de la ficción.

Todo lo que es y no es se sumerge en la sombra o en la nube de una realidad paradójica en tanto fruto de una tensión del propio lenguaje, de la vehemencia ontológica del «es» cortada por la literalidad crítica del «no es», dice Ricoeur. Es sorprendente la dialéctica de esta «tensión interior a la fuerza lógica del verbo ser», para cuyo esclarecimiento «es necesario hacer aparecer un 'no es', implicado en la interpretación literal imposible, pero presente en filigrana en el 'es' metafórico» (Ricoeur, 1980: 333). Se trata de un reino de tensiones aparentemente contradictorias pero brillantes, las cuales permiten vivificar y dar significado real a la metáfora.

\subsection{Penser plus}

La metáfora es ficción, pero constituye mundo: el mundo enriquecido en su realidad por un pensar conceptual ampliado, el penser plus de Ricoeur (1975: 384; 1980: 409). Veremos cómo conceptualizarlo en lo posible, siguiendo lo que ya se ha insinuado en los oxímoros de antes, cuyo contenido conceptual es precisamente el que caracteriza ese 'pensarplus'.

Lo que interesa, con el fin de activar esa nueva perspectiva sobre la realidad a la que fuerza la imaginación en la figuración poética de la metáfora, es que la intrusión de una incongruencia «hace pensar». La «impertinencia» (palabra que Ricoeur utiliza muchas veces a lo largo de su obra, siempre en el sentido de la «impertinencia semántica» de Jean Cohen ${ }^{10}$ ) de la metáfora causa un desorden semántico que obliga a la

\footnotetext{
${ }^{10}$ Término de uso habitual dentro de la renovación estructuralista de la crítica poética francesa desde la aparición del conocido libro de Cohen (1966). En esta obra se analizan figuras de desestructuración poética, descomposición sémica o transgresión metafórica, en las que el lenguaje rebasa su función informativa o sus signifiés notionnels corrientes. Todos estos aspectos semánticos interesan sobremanera a Ricoeur, máxime cuando Cohen (1966: 224) afirma, en referencia a ellos, que la palabra poética es a la vez muerte y resurrección del lenguaje, o de lenguajes. La «impertinencia» es una de esas figuras más efectivas porque con ella se produce modélicamente la ruptura en el lenguaje poético de la relación ordinaria entre sujeto y predicado. Esto da lugar a eminentes fautes de langue, como la del ejemplo preferido por Cohen: la jonction «bleus angélus» del verso de
} 
reorganización de nuestro ordenamiento conceptual de las cosas, con vistas a probar y mantener su coherencia. Las metáforas suponen colocarse a una «distancia consciente, intencional, en la contemplación del mundo natural» (M. Hester), son como weapons directed against reality (K. Harris) que necesitan esa distancia para ser lanzadas a la redescripción del mundo (Biebuyck, 1998: 306). Esas armas dirigidas contra la realidad convencional resultan incongruentes, impertinentes y desordenadoras. La distancia a ella, que promueve su observación y el cálculo de la estrategia destructora -al menos deconstructora o desordenadora-, funda su consciente incongruencia e impertinencia.

Esa especie de escisión que desde el lenguaje causa su uso literario (poético, metafórico, reflexivo) en el pensar, y de paso en el imaginar, esa distancia de consciencia describe bien, por otra parte, lo que puede que suceda en la base de la gran creación literaria; y lo que de hecho constituye tanto «el alma» como el problema diario de la interpretación literaria: que "d'un côté elle veut la clarté du concept -de l'autre, elle cherche à préserver le dynamisme de la signification que le concept arrête et fixe» (Ricoeur, 1975: 383). Las grandes metáforas, en medio, sobrepasan olímpicamente esa dicotomía: son vivas y suficientemente claras, libres y sin constricción alguna, impertinentes semánticamente en el lenguaje y pertinentes heurísticamente en la interpretación y constitución del mundo. No necesitan la claridad del concepto y les sobra dinamismo significativo. Su mundo no es de este mundo que el concepto coagula, fija, delimita, define. Ellas se mueven libre y soberanamente en la indeterminación conceptual, más allá del pensar normal, en el mundo de ficción del penser plus.

La metáfora obliga al pensamiento conceptual a pensar más y más allá, a seguir pensando más allá de sus límites, pues donde fracasa ya el entendimiento la imaginación sigue teniendo poder para presentar la idealidad de las cosas. El fondo del penser plus radica en las «referencias de segundo grado" que percibe cuando se acerca a la poesía; dicho de

\footnotetext{
Mallarmé: «Et du métal vivant sort [l'Azur] en bleus angélus!» (L'Azur, 1864). Cf. Mallarmé (1982: 52) y Cohen (1966: 128 ss.). Sobre «impertinence et pertinence sémantiques», cf. Ricoeur (1975: 199, 259, 369; 194, 368). Sobre la «impertinence» misma (lo contrario de "pertinence» y su código de normalidad, que aquí interesan menos porque con ellos no puede construirse una semántica tan refinada como la de la «métaphore vive»), cf. Ricoeur (1975: 195-199, 211-216).
} 
otra manera, a la kantiana: como la poesía, la metáfora proporciona a la imaginación un impulso a pensar -aunque no sea de manera explícitamás de lo que se puede pensar en un concepto determinado o de lo que se puede comprender en una expresión determinada de la lengua ${ }^{11}$. Y es en ese pensar ampliado donde se aclara definitivamente la noción de metáfora viva, que es viva no solo porque vivifica un lenguaje constituido, sino porque inscribe el impulso de la imaginación en el concepto mismo (Ricoeur, 1975: 384).

La metáfora es así una estrategia discursiva para preservar y desarrollar tanto el poder creativo del lenguaje como, con él, el poder heurístico de la ficción. Lo hace basándose en la conexión previa entre sentido (organización interna) y referencia (poder de relación con una realidad exterior al lenguaje) en el discurso.

Como resumen de lo dicho: la metáfora da el salto desde dentro del lenguaje (sentido) al afuera real (referencia). Vivifica el lenguaje y el pensamiento con el impulso de la imaginación al inscribirlos en un "pensar más» (y un 'decir más' correspondiente) que los lleva más allá también de la rigidez conceptual del mundo.

\subsection{Metáfora y referencia}

En cualquier caso, la discusión de estrategias, referencial y no referencial, ha de darse donde insiste Ricoeur tantas veces: no en las palabras, ni siquiera en las unidades del discurso, las frases, sino en las totalidades del discurso o de la obra; y según tres criterios crítico-literarios clave y claros: estructura, género y singularidad.

La question de la référence se joue ici au niveau non de chaque phrase, mais du 'poème' considéré selon les trois critères de l'œuvre: 'disposition', subordination à un 'genre', production d'une entité 'singulière'. Si l'énoncé métaphorique doit avoir une référence, c'est par la médiation du 'poème' en tant que totalité ordonnée, générique et singulière. Autrement dit, c'est pour autant que la métaphore est un 'poème en miniature', selon le mot de Beardsley, qu'elle dit quelque chose sur quelque chose (Ricoeur, 1975: 279).

${ }^{11}$ Ricoeur se refiere y cita aquí los parágrafos A 190-193 de la Crítica de la razón pura de Kant, también el famoso 49 de la Crítica del juicio en la página anterior. 
Y aquí, en torno a la referencia metafórica posibilitada por el penser plus, comienza el interesantísimo núcleo de la discusión de Ricoeur con los grandes especialistas y su superación positiva. Ricoeur no niega la validez de las críticas a la referencia metafórica ni las tesis que las sostienen, más bien se apoya en ellas y recoge aspectos suyos. Lo hace sobre dos bases: la primera, reduciendo el ámbito de sentido de esas críticas al "definido por las normas del discurso descriptivo»; la segunda, considerándolas en conjunto como «la condición negativa para extraer un modo más fundamental de referencia» (Ricoeur, 1980: 308).

Expone las críticas lingüísticas (de Roman Jakobson, sobre todo), las crítico-literarias (de Northrop Frye, principalmente), incluso las epistemológicas del viejo positivismo lógico (Carnap) en sus influjos literarios (en la Nueva Retórica francesa, sobre todo). De la lingüística general de Jakobson se queda con su "preciosa sugerencia» sobre la ambigüedad de la referencia y su desdoble, y con la alusión al «admirable» això era $i$ no era (Ricoeur, 1975: 282). En torno a la Nueva Retórica comenta ideas de varios autores: el discurso opaco o sin referencia de Todorov, la función exclusivamente connotativa de la poesía en Jean Cohen, o la negación de la función referencial del discurso metafórico de la Retórica general del Grupo de Lieja, por ejemplo. Ideas todas que es capaz de dar la vuelta de algún modo en beneficio de su metáfora viva.

Ricoeur muestra a la nueva retórica, en efecto, que se halla enclaustrada en la opacidad de la metáfora-palabra y que desde el interior de sus propios límites ella misma remite a una teoría de la metáfora-enunciado (denotativa, objetivamente significativa), la cual no puede elaborar, sin embargo, sobre las bases de su propio sistema de pensamiento. Un diálogo en común redundaría tanto en los propios intereses de la teoría de la metáfora viva (profundizar los postulados de la referencia), como en los de la nouvelle rhétorique («restituir su envergadura entera a la teoría de las figuras», más allá de la de los tropos en la que está enclaustrada). Eso hace Ricoeur (1975: 9, 173-178, 219, 286-288), construyendo en parte su discurso por su confrontación con ella.

De la crítica literaria de Frye, Ricoeur se queda con algún aspecto de su pensamiento, como la noción de «lo hipotético». Frye afirma que el poema no es ni verdadero ni falso, sino hipotético, y lo compara con la obra del matemático puro, que está conforme con la lógica de sus 
hipótesis, pero sin relacionarse con una realidad descriptiva. Ricoeur le contesta con unas preguntas que insinúan perfectamente el mundo peculiar y profundamente humano de la metáfora, que ni necesita ni tiene que ver con ese tipo de realidad (ni matemáticamente formal, ni objetivamente descriptiva) para ser real:

Mais 'l'hypothèse poétique' n'est pas l'hypothèse mathématique; c'est la proposition d'un monde sur le mode imaginatif, fictif. Ainsi la suspension de la référence réelle est la condition d'accès à la référence sur le mode virtuel. Mais qu'est-ce qu'une vie virtuelle? Peut-il y avoir une vie virtuelle sans un monde virtuel dans quoi il serait possible d'habiter? N'estce pas la fonction de la poésie de susciter un autre monde -un monde autre qui corresponde à des possibilités autres d'exister, à des possibilités qui soient nos possibles les plus propres? (Ricoeur, 1975: 288, cf. 284).

Así es: la hipótesis poética propone un mundo imaginativo, ficticio, un mundo virtual donde, sin embargo, es posible habitar; otro mundo, aquí mismo, con otras posibilidades de existencia, que quizá sean las más propiamente humanas.

Ante la apariencia mencionada de que el discurso poético, que parece esencialmente no referencial y centrado en sí mismo, choque con la posibilidad de que el discurso metafórico diga algo sobre la realidad, Ricoeur reacciona oponiendo a ello «un poder de referencia de segundo grado» que constituye la verdadera "referencia poética», en la que ya no hay que hablar solo de doble sentido, sino de "referencia desdoblada». Una expresión -que toma de Jakobson y que utiliza muchas veces, sobre todo en el estudio VII- inmersa en el contexto de la tensión de lo que llama «la verdad metafórica»; tensión que supera el doble sentido en el desdoble de lo mismo, y que se plasma en la mencionada "paradoja de la cópula» del enunciado, según la cual «être-comme signifie être et n'être pas», como sucede en el «això era y no era (sic)» (Ricoeur, 1975: 398, cf. 376).

Acude a Jakobson en el momento de la verdad, nunca mejor dicho, de la verdad metafórica y de la tensión que supone; en el momento en que hay que dar cuenta de la complejidad de la referencia -poética o 
metafórica- desdoblada, cercana a la ironía ${ }^{12}$ y a la ambigüedad ${ }^{13}$. Cercana más bien a un mundo liberado, por suspensión, de la referencia descriptiva y a un lenguaje sustraído de la función didáctica del signo "pour ouvrir l'accès à la réalité sur le mode de la fiction et du sentiment» (Ricoeur, 1975: 289). Y cita entonces textualmente a Jakobson, redondeando así contundentemente este marco más que semántico (sémantique plus, diríamos) del profundo influjo metafórico-poético en y del lenguaje: "La poésie ne consiste pas à ajouter au discours des ornements rhétoriques, elle implique une réévaluation totale du discours et de toutes ses composantes quelles qu'elles soient» (Ricoeur, 1975: 289).

Ricoeur insiste en calmar la «desazón» que le produce el sentido tensional de la verdad metafórica acudiendo, además, a una teoría de la «denotación generalizada», próxima a la de Nelson Goodman en Languages of Art, en cuyo amplio marco quepa inscribir la referencia metafórica y cuya generalidad posibilite superar la oposición entre denotación y connotación (Ricoeur, 1975: 290 ss.); así como a la afinidad establecida por Max Black en Models and Metaphors entre el funcionamiento de la metáfora en las artes y el de los «modelos» en las ciencias; en este caso para justificar concretamente su concepto de "redescripción por la ficción», concluyendo que «esta afinidad en el plano heurístico [entre modelo y metáfora] constituye el principal argumento de esta hermenéutica de la metáfora» (se refiere a la suya) (Ricoeur, 1980: 15; cf. 323 ss.) ${ }^{14}$.

${ }^{12}$ Frye, en un contexto parecido, deduce que toda estructura literaria es irónica «because 'what it says' is always different in kind or degree from 'what it means'»; por eso, adhiriéndose a la "nueva crítica», afirma, por ejemplo, «that poetry is primarily (i. e. literally) an ironic structure». (Frye, 1990: 81, 116). Cf. esta interesante idea en Ricoeur (1980: 305; 1975: 285). El tema dilecto de Frye es el de la ironía, como ya subraya Bloom en el prólogo («a formidable ironist»); no hay más que ver cuánto habla de ella en su famoso libro Anatomy of Criticism (1957). Entre tantos aspectos interesantes no se puede dejar de citar su concepto de "provincianismo irónico» (búsqueda de objetividad completa) o la relación de afinidad de lo irónico con lo paradójico y con lo anti-alegórico (Frye, 1990: vii, 62, 91). Para lo que se ha dicho sobre poesía y mito, es de obligada referencia el ensayo «Archetypal Criticism: Theory of Myths» en Frye (1990: 131-242).

13 Cf. Ricoeur (1975: 282), donde con palabras de Jakobson describe el juego poético de la ambigüedad (y el del desdoblamiento).

14 En cuestiones de referencia y semántica, Ricoeur acude a Goodman y a Black numerosas veces y en el sentido dicho: a Goodman sobre todo en el estudio VII, 3 ( UUna teoría de la denotación generalizada»); a Black en el III, 3 y 4 («Gramática lógica y semántica» y «Crítica literaria y semántica»), y en el VII, 4 («Modelo y metáfora»). Cf. Ricoeur (1975: 109 ss., 122 ss., 302-310). 


\subsection{Revitalización del lenguaje. Conclusión.}

Hermenéutica de la metáfora de muchas dimensiones, de la que al final hay que concluir, volviendo al aixó era i no era («que contiene in nuce todo lo que se puede decir de la verdad metafórica», veíamos), lo que ya anunciaba Ricoeur en el prefacio de su libro (1975: 11): que el «lugar» propio de la metáfora, «son lieu le plus intime et le plus ultime», no es el nombre ni la frase, ni siquiera el discurso, sino "la cópula del verbo ser», en cuya tensión suprema «se siente en casa».

En su aspecto más formal, dicha tensión sería la que produce el contraste entre equívoco y repetición, entre diáfora y epífora. Esa tensión define conclusivamente la metáfora misma, que refresca así la tensive aliveness del lenguaje (de la que habla Philip Wheelwrigh en Metaphor and Reality), por la que este es capaz de mediar en todos los conflictos entre perspectiva y apertura, designación y sugerencia, imaginería e impacto, concreción y plurisignificación, precisión y resonancia afectiva, dice Ricoeur. Y además de avivar esta exuberante tensión interna del lenguaje, lo abre a nuevas dimensiones semánticas, según se ha planteado ya. Respecto a ese carácter tensive-alive que Wheelwrigh asigna al lenguaje, Ricoeur (1975: 315) concluye:

La métaphore, plus particulièrement, recueille ce caractère tensive du langage, par le contraste de l'epiphor et de la diaphor: l'epiphor rapproche et fusionne les termes par assimilation immédiate au niveau de l'image; la diaphor procède médiatement et par combinaison de termes discrets; la métaphore est la tension de l'epiphor et de la diaphor. C'est cette tension qui assure le transfert même du sens et qui donne au langage poétique son caractère de «plus-value» sémantique, son pouvoir d'ouverture sur de nouveaux aspects, de nouvelles dimensions, de nouveaux horizons de la signification.

Esos nuevos horizontes de plusvalía semántica, abiertos por la metáfora, son aspectos o dimensiones de un lenguaje poético lógicamente tenso e implosionado semánticamente y de una realidad redescrita y configurada sui generis a través de sus filtros referenciales verificativos. Esa realidad, en palabras de Wheelwrigh, es "presential and tensive, coalescent and interpenetrative, perspectival and hence latent -brief, revealing itself only partially, ambiguously, and through symbolic indirection" (Ricoeur, 1975: 315). No puede mostrarse de otro modo la realidad 
constituida por la referencia y verdad metafóricas que así: simbólicamente oblicua, virtual pero real, ficcional pero habitable, desdoblada entre ser y no ser, mímesis y mito, coalescencia y latencia, ambigüedad e ironía, epifora y diáfora. Esa tensive aliveness condensa al final coherentemente el mundo peculiar que crea el lenguaje poético recuperado por la metáfora viva.

Siempre desde ese punto de vista, ajeno al racionalismo, pero enriquecedor de lo real precisamente por ello, hemos de concluir sobre todo lo visto que la revitalización del lenguaje poéticamente fosilizado de Emerson o de Nietzsche es posible por una comprensión «viva» de la metáfora como la de Ricoeur, en la que, por obra del análisis lingüísticofilosófico, la metáfora pasa de la lírica a la ficción. Esto es, se distancia del mero recurso estético que era en la retórica y adquiere sentido simbólico: el de una representación perceptible de una idea, de una forma de exteriorizar el pensamiento o de explicitar oscuridades y carencias del lenguaje descriptivo, enriqueciéndolo semánticamente. Dicho de otra manera, la metáfora se traslada de la retórica a la apofántica ${ }^{15}$ : se convierte en un enunciado peculiar sobre el mundo, emite un juicio peculiar sobre la realidad, la cual condiciona, redescribiéndola a su modo.

La metáfora adquiere en Ricoeur definitivamente el sentido de una forma de conocimiento $\mathrm{y}$, de esa manera, no solo valor hermenéutico sino también constitutivo de mundo. A su modo, desde luego, igual que el concepto lo hace al suyo. Así es como la teoría de la metáfora viva recupera el esplendor poético del lenguaje y bajo el gesto «de la ficción y el sentimiento» enriquece el mundo.

\section{BIBLIOGRAFÍA CITADA}

Barfield, O. (1928): Poetic Diction, a Study in Meaning. London, Faber \& Gwyer.

BIEBUYCK, B. (1998): Die poetische Metapher: ein Beitrag zur Theorie der Figürlichkeit. Würzburg, Königshausen \& Neumann.

CAMPBELL, J. (2013): Las extensiones interiores del espacio exterior. La metáfora como mito y como religión. Villaür, Atalanta.

\footnotetext{
${ }^{15}$ Sobre las peculiaridades paradójicas de esta apofántica, cf. Ricoeur (1975: 388).
} 
CoHEN, J. (1966): Structure du langage poétique. Paris, Flammarion.

Emerson, R. W. (1950): The Complete Essays and Other Writings. B. Atkinson (ed.). New York, The Modern Library.

FrYe, N. (1990) Anatomy of Criticism. Princeton-Oxford, Princeton University Press.

Mallarmé, S. (1982): Poesía. Ed. bilingüe de F. Gorbea. Barcelona, Plaza \& Janés.

LACHMAN, G. (2013): Una historia secreta de la consciencia. Villaür, Atalanta.

NiETzSCHE, F. (1970): Sobre verdad y mentira en sentido extramoral. En: Obras completas, Buenos Aires, Ed. Prestigio, I, págs. 541-556.

PRIKETT, S. (1986): Words and the Word: Language, Poetics and Biblical Interpretation. New York, Cambridge University Press.

Reguera, I. (2018): Posmodernidad, melancolía y mal. Sevilla, Athenaica.

Ricoeur, P. (1975): La métaphore vive. Paris, Éditions du Seuil.

Ricoeur, P. (1980): La metáfora viva. Madrid, Ediciones Europa.

Ricoeur, P. (2004): Finitud y culpabilidad. Madrid, Trotta.

ViCKery, J. B. (ed.) (1966): Myth and Literature: Contemporary Theory and Practice. Lincoln, University of Nebraska Press.

Ángela PÉREZ CASTAÑERA IES Luis de Morales (Arroyo de la Luz, Cáceres) angelazulcc@gmail.com https://orcid.org/0000-0001-9427-7032 